\title{
EMPIRICAL STUDY ON DETERMINANTS FOR THE CONTINUED USE OF MOBILE SHOPPING APPS
}

\author{
Dalsang Chung, Governors State University, dchung@govst.edu \\ Sun Gi Chun, Alabama State University, sungichuhn@alasu.edu \\ Hae Yeon Choi, Savannah State University, choi@savannahstate.edu
}

\begin{abstract}
The paper provides an in-depth examination on shoppers' behaviors towards mobile shopping applications (apps). The study incorporates the Expectancy Confirmation Model (ECM) in order to understand and prove what hinders or encourages mobile shoppers to continue using mobile shopping apps. Thus, effects of factors on the continued intention to use mobile shopping apps were examined including confirmation, perceived ease of use, usefulness, enjoyment, security/privacy, localization/instant connectivity, personalization, and satisfaction. The results of the study show that the continuation of using mobile shopping apps is primarily dependent on mobile shoppers' satisfaction with the mobile shopping. Confirmation, perceived ease of use, usefulness, enjoyment, and personalization are important determinants while security/privacy and localization/instant connectivity are not significant. The findings may provide useful knowledge to all who are involved in encouraging and promoting the use of the mobile apps for potential shoppers.
\end{abstract}

Keywords: Mobile Shopping, Mobile Shopping Apps, Determinants, Continued Use

\section{INTRODUCTION}

Mobile shopping has become a favored approach for modern customers to purchase products or services using mobile apps. This has been greatly boosted by the continuously increasing number of mobile phone users. During the Black Friday shopping season of 2015, major U.S. retailers watched the average of $45 \%$ increase in the use of mobile shopping apps for the shopping, which was considered as the result of retailers' investment in designing apps for shoppers to experience shopping in the easier way (Gustafson, 2015). During the season, Amazon was the leader for mobile shoppers downloading apps on Apple iOS while Wish, Wal-Mart, eBay, and Target followed in terms of the number of downloads on iOS devices. BestBuy and Staples were leaders in terms of the number of downloads of retail apps on Android mobile devices. Mobile apps on Apple iOS and Android allow shoppers to find special discounts, preview deals, establish shopping preferences, and easily complete transactions using the pre-set payment methods, which provides rich experience to mobile shoppers.

The Expectancy Confirmation Model (ECM) is known to be the first model explaining what motivates people to continue using mobile apps in electronic commerce. While ECM may explain why some users discontinue the use of information systems (IS) after they have pre-accepted it, it is still insufficient to explain why users discontinue their use even though they are satisfied with the post-use experience (Hung et al, 2012). While research on the continued use of mobile shopping apps is still in its infancy, what is needed is to better understand determining factors that influence the adoption of mobile shopping apps. In order to better understand and develop mobile shopping apps, developers and providers need to find out how customers' attitudes and beliefs may affect the use of mobile shopping apps. Through the proper understanding of customers' considerations and emotional feelings, managers for retailers can develop strategies for building and promoting specific apps that customers will want to use (Lu \& Su, 2009). Smart phones have been developed very rapidly with advanced capabilities and efficiencies, which makes it a lot easier for consumers to purchase products or services through mobile apps. For example, mobile apps can now supply customers with the capability to compare among thousands of products, which better enables them to choose by means of competitive pricing (Chen, 2013). 


\section{Issues in Information Systems \\ Volume 17, Issue II, pp. 34-43, 2016}

Even though there have been drastic improvements in the mobile equipment, the environment for mobile shopping faces a few issues. One major problem is that the bandwidth of the mobile Internet is narrower than that of fixed lines, and the mobile Internet may be sometimes disconnected without any prior warning. Another problem is that mobile devices have smaller screens, limited computing capabilities, battery power, and memory. Even skilled users may get panic when using mobile apps because many complicated apps have been placed into such a tiny device, which negatively affects users' experience ( $\mathrm{Lu} \& \mathrm{Su}, 2009)$. Also, users feel fear for the possibility that personal information is at risk, which is one of major roadblocks for using mobile shopping apps (Chen \& Lauffer, 2010). Many people have mobile shopping experience with the use of mobile apps, but are unwilling to continuously use mobile apps to do the shopping, which makes the growth of mobile shopping apps relatively slow (Hung et al, 2012). In the mobile commerce context, most customers can be classified into mobile shoppers (m-shoppers) who use their devices to purchase, and mobile users who use their devices to communicate (Hung et al, 2012). The objective of the study is to investigate on determining factors for motivating or demotivating shoppers to use mobile shopping apps even though they may have had a positive experience with the use of mobile shopping apps. Retailers have quickly realized that mobile apps are a new channel for them to reach out to potential as well as existing customers.

\section{LITERATURE REVIEW}

\section{Expectation Confirmation Model (ECM)}

Based on the literature review from the previous studies, there are three models, ECM, TAM and hybrid model integrating ECM and TAM for explaining continued use of new technologies. Comparing three models, all three models met the goodness fit criteria while some authors said that TAM explained the continued intention use better than $\operatorname{ECM}($ Hong et al, 2006). Thus, in our study, we adopt the ECM.

According to the prior research, ECM model has been widely used in many different fields. For instance, it is used in the consumer behavior area to study consumer satisfaction and post-purchase behavior like repurchasing and complaining in the service marketing area (Oliver, 1980) and the online banking area (Bhattacherjee, 2001). Different from the technology adoption model (TAM) dealing only with the pre-behavior, ECM was devised to explore the post-behavior as well as pre-behavior. Based on the study from Oliver (1980), consumers' repurchase intentions are highly dependent on the prior satisfaction, while satisfaction is obtained from the disconfirmation and expectation for products or services. ECM is briefly described as follows: firstly, consumers form expectations for specific products or services before the purchase. Secondly, consumers form perceptions about the performance of the products or services ter using and accepting them. Thirdly, with the assessment of perceived performance, the actual performance may meet the expected standard, fail to meet the expected standard, or even exceed the expected standard, which is called disconfirmation of beliefs. The expectation and perceived level of confirmation will positively affect satisfaction when the expectation of the products or services is met, and consumer's expectations are confirmed. Conversely, when performances are worse than expectations, it is negatively disconfirmed.

Eventually, satisfied consumers form a repurchase intention while dissatisfied consumers would discontinue the subsequent use. Satisfaction is viewed as the key to build and retain a loyal base of long-term consumers. Applying the ECM model to the IS field is adequate since IS users' continuance decisions are similar to consumers' repurchase decisions. Bhattacherjee (2001) has pointed out that IS customers' continuance decisions show some features that are similar to consumers' repurchasing decisions because both are influenced by the prior use experience, which can potentially lead to ex post reversal of the initial decision. Furthermore, Bhattacherjee theorized that post-adoption would influence on IT users' satisfaction. Consequently, ECM is used to predict users' continuance behavior based on the extrinsic motivations like satisfaction and perceived usefulness. To adapt ECM into a different context, authors accommodate ease of use, enjoyment, security/privacy, localization/instant connectivity, and personalization in the research model to test if consumers may continue to use mobile shopping apps when they feel more secure and get more benefits from mobile apps. 


\section{Issues in Information Systems \\ Volume 17, Issue II, pp. 34-43, 2016}

\section{Possible Factors Affecting Consumers' M-shopping Through Apps}

Perceived ease of use plays an important role in the Internet shopping through apps, although it is supposed to be beneficial to consumers when they use mobile shopping apps. Also, mobile apps are to be designed for consumers to easily browse, search, checkout, and pay for purchasing products or services, which affects the continued use of mobile apps. If the effort outweighs the benefit of purchasing through mobile shopping apps, potential consumers would rather purchase products or services through the conventional channels. Usefulness is the individual's belief that using mobile shopping apps would gain specific rewards and increase performance. The construct of perceived usefulness affects the intention to use apps for Internet consumers. Additionally, people tend to use or not use apps to the extent they believe shopping apps would help perform their job better. As an intrinsic factor, enjoyment has a positive impact on the intention to use the apps for m-shopping. Perceived enjoyment is defined as the extent to which the activity of using the computer is perceived to be enjoyable in its own right, apart from any anticipated performance consequences (Davis et al, 1992). Consumers who perceive more fun and enjoyment by using mobile phones may tend to perform with more positive attitudes toward using mobile apps.

Besides enjoyment, security and privacy can also affect the use of mobile shopping apps. Security is the capability that protects data and information from unauthorized persons or systems. Security is about one's judgment concerning the security of using mobile shopping apps. Also, Liu et al (2005) developed the privacy-trust-behavioral intention model indicating that the primary reason for not using online shopping website or apps is a lack of trust in the electronic transactions. People are reluctant to input their personal information (i.e. address, credit card number, date of birth) through mobile apps because they are concerned that their information will be shared and abused by unauthorized third parties.

Localization/instant connectivity is the characteristic of being able to show the current position of the consumer at a specific time so that shoppers can easily locate products or services needed at the right time and place, and mobile apps help shoppers reduce mental efforts for shopping. It is useless to shoppers if the capability to access products or services at the shoppers' current location is not available. The ability to search for and get access to the right information as quickly as possible has a significant impact on whether consumers will continue to use mobile apps. Personalization is referred to as the mobile user's individualization and differentiated customer service (Raisinghani, 2004). Mobile shopping apps have been continuously improved with the trend of upgraded capabilities of mobile devices. Apps should be able to provide more personalized services that cater to each individual shopper such as shopping preferences. Confirmation is positive when their shopping experience using mobile shopping apps was better than what they expected. Confirmation can solidify shoppers' decision to continue using apps when their expectations were met or surpassed. In ECM, there are positive relationships among confirmation, ease of use, usefulness, enjoyment, security, privacy, localization/personalization, and satisfaction which influence the continual use of mobile shopping apps. If the protection of mobile shoppers' security/privacy can be confirmed, existing trust leads to the continual use of mobile shopping apps ( $\mathrm{Lu} \& \mathrm{Su}, 2009)$.

\section{Research Model and Hypotheses}

Hypotheses to be tested for the study are as follows: (Refer to Figure 1)

H1: Mobile shoppers' confirmation has a positive influence on the perceived ease of use of mobile shopping apps. H2: Mobile shoppers' confirmation has a positive influence on the perceived usefulness of mobile shopping apps. H3: Mobile shoppers' confirmation has a positive influence on enjoyment of mobile shopping apps.

H4: Mobile shoppers' confirmation has a positive influence on the security/privacy of mobile shopping apps.

H5: Mobile shoppers' confirmation has a positive influence on the localization/instant connectivity of mobile shopping apps. 


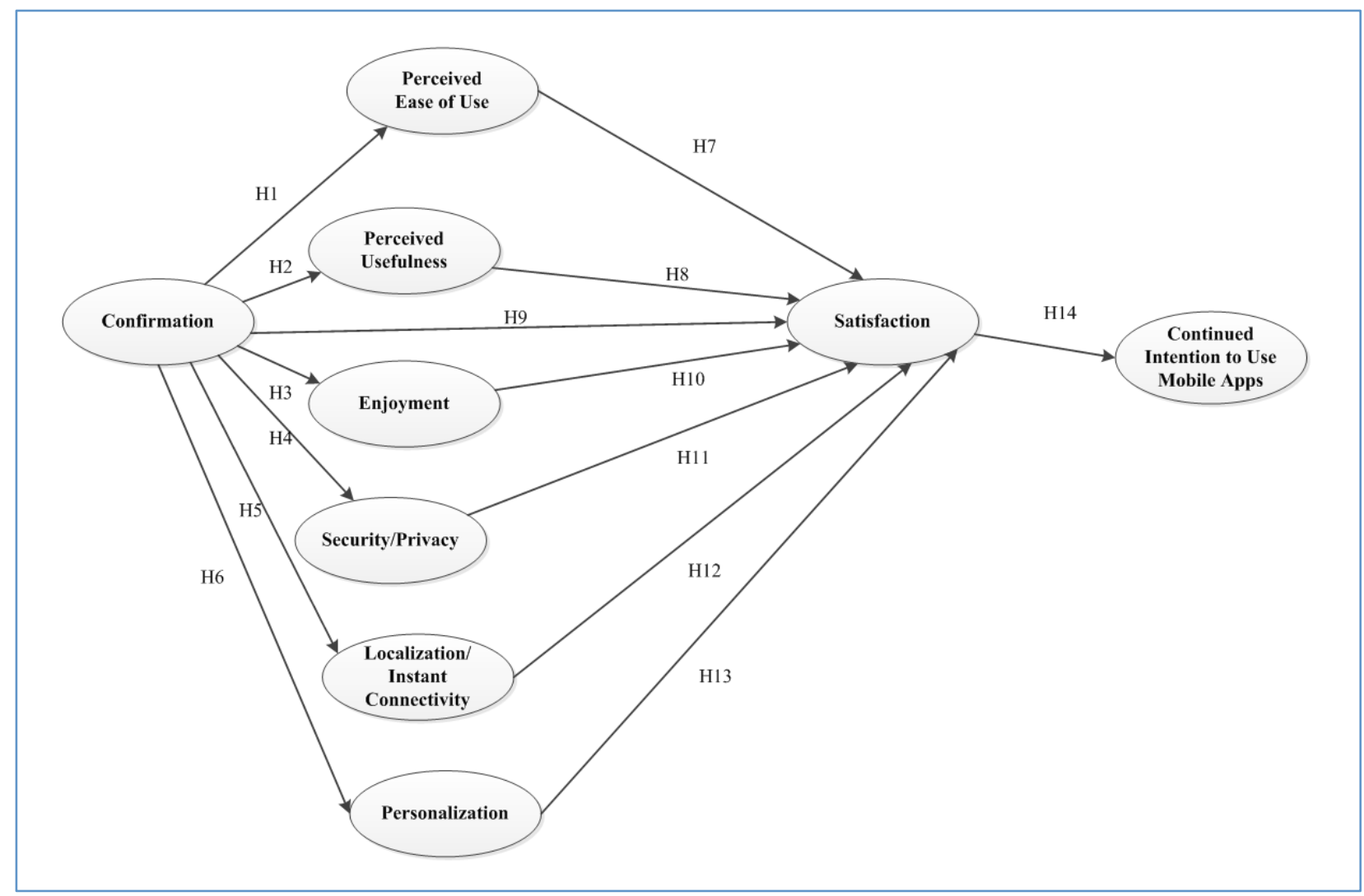

Figure 1. Research Model

H6: Mobile shoppers' confirmation has a positive influence on personalization of mobile shopping apps.

Perceived ease of use refers to the simplicity and user friendliness of mobile shopping apps. Since behavioral intent depends on cognitive choice, potential users of mobile shopping apps can respond either favorably or unfavorably towards engaging in the continued use of mobile shopping apps (Chong, 2013). Poorly designed apps can be very frustrating and time consuming for shoppers, which in turn can have a negative effect on satisfaction. Thus, the following hypothesis is proposed:

H7: Mobile shoppers' perceived ease of use for mobile apps has a positive influence on satisfaction.

Perceived usefulness refers to the shoppers' cognition that the usage of mobile shopping apps will improve their shopping experience. In the ECM, perceived usefulness is considered to be a type of post adoption expectation upon interacting with mobile shopping apps (Chong, 2013). It enhances users' shopping experience and effectiveness, and can reduce the time spent browsing complicated websites.

H8: Mobile shoppers' perceived usefulness for mobile apps has a positive influence on satisfaction.

Confirmation has a positive effect on satisfaction if expectations are met or surpassed. Satisfaction is affected by disconfirmation and expectation with disconfirmation indicating the gap between expectations and perceived performance (Chen et al, 2010).

H9: Mobile shoppers' confirmation for mobile apps has a positive influence on satisfaction. Enjoyment in the study refers to users' lasting joy and immediate pleasure obtained from the usage of mobile shopping apps. Enjoyment positively affects the loyalty of mobile shoppers, resulting in increased satisfaction. Enjoyment tells the extent to which mobile shopping apps are enjoyable, pleasurable, and interesting. Thus, the following hypothesis is proposed: 


\section{Issues in Information Systems \\ Volume 17, Issue II, pp. 34-43, 2016}

H10: Mobile shoppers' enjoyment for mobile apps has a positive influence on satisfaction.

Security refers to the confidence of mobile shopping apps users in the capability of apps for keeping their personal information safe and secure. Users of mobile shopping apps are also confident in the system to believe that payment transactions are secure, and no unauthorized party is overseeing the shopping process. Shoppers feel confident that their transactions are safe. There are risks of malicious apps that may steal their personal information. These are a few problems that mobile shoppers face when deciding to use mobile apps, and may be one of the major reasons why some shoppers are hesitant to use mobile apps in the first place. Confidence in security leads to satisfaction. Privacy refers to how comfortable mobile shoppers are in the capability of mobile shopping apps to keep their personal information private. They believe that information such as credit card numbers and addresses will not be shared with unauthorized third parties. Some shoppers may believe that too much personal information is required and collected by apps, which may force them to discontinue using apps. Thus, the following hypothesis is proposed:

H11: Mobile shoppers' security/privacy concern for mobile apps has a positive influence on satisfaction.

Localization/instant connectivity allows mobile shoppers to get access to products or services available at shoppers' current location as quickly as possible without putting too much effort, which leads to satisfaction. The capability to search for and get access to the right information as quickly as possible has a significant impact on whether consumers will continue to use mobile apps.

H12: Mobile shoppers' localization/instant connectivity using mobile apps has a positive influence on satisfaction.

Mobile apps can provide more personalized services such as shopping preferences, which affects satisfaction.

H13: Mobile shoppers' personalization with mobile apps has a positive influence on satisfaction.

Satisfaction indicates a sense of gratification or disappointment obtained after using mobile apps and comparing their performance with expectations. Satisfaction plays a major role in determining whether shoppers will continue using mobile shopping apps. Satisfaction is a by-product of ease of use, usefulness, enjoyment, security/privacy, localization/instant connectivity, personalization, and confirmation. In an empirical study on the mobile shopping, satisfaction was found to be the major determinant for the continued use of Internet shopping (Chen et al, 2010). In order for shoppers to continue using mobile shopping apps, some positive experiences are required. There needs to be some level of satisfaction for shoppers to keep using mobile apps.

H14: Mobile shoppers' satisfaction has a positive influence on the continued intention to use mobile shopping through apps.

\section{RESEARCH METHODOLOGY}

In order to test the hypotheses, a survey was conducted to students and professionals. A survey questionnaire was designed and deployed online using Survey Monkey to validate the hypotheses of the study. The survey instrument consisted of questions about demographics of participants, installations of mobile shopping apps, mobile app shopping expenditures, and their frequency of usage of mobile apps for purchasing merchandise. Then, thirty-two (32) items for nine (9) constructs were statements to measure respondents' confirmation, perception of six (6) factors, satisfaction, and continued intention to use mobile apps. Respondents' perception of six (6) factors were ease of use, usefulness, enjoyment, security/privacy, localization/instant connectivity, and personalization. Respondents replied to the statements on a 5 point Likert scale, that is, one (1) for strongly agree and five (5) for strongly disagree.

201 usable responses to the survey were collected. Respondents' demographic information in terms of gender, age, and education background was as follows. Refer to Table 1 below. 


\section{Issues in Information Systems}

Volume 17, Issue II, pp. 34-43, 2016

Table 1. Demographics

\begin{tabular}{|c|c|c|c|c|c|}
\hline Age & Number (Percent) & Gender & $\begin{array}{l}\text { Number } \\
\text { (Percent) }\end{array}$ & Education & $\begin{array}{l}\text { Number } \\
\text { (Percent) }\end{array}$ \\
\hline$<=20$ & $40(20 \%)$ & Male & $103(51 \%)$ & High School & $13(6 \%)$ \\
\hline $21-30$ & $102(51 \%)$ & Female & $98(49 \%)$ & Some College & $70(35 \%)$ \\
\hline $31-40$ & $32(16 \%)$ & & & Bachelor's Degree & $67(33 \%)$ \\
\hline$>=41$ & $27(13 \%)$ & & & Graduate Degree & $51(25 \%)$ \\
\hline $\begin{array}{c}\text { Mobile } \\
\text { Device } \\
\text { Platform }\end{array}$ & Number (Percent) & $\begin{array}{l}\text { Number of } \\
\text { Shopping } \\
\text { Apps on } \\
\text { Smartphone }\end{array}$ & Number (Percent) & $\begin{array}{l}\text { Devices Used for } \\
\text { Mobile Shopping }\end{array}$ & $\begin{array}{l}\text { Number } \\
\text { (Percent) }\end{array}$ \\
\hline Android & $95(47 \%)$ & 0 & $58(29 \%)$ & Smartphone & $63(31 \%)$ \\
\hline Apple iOS & $93(46 \%)$ & $1-2$ & $57(28 \%)$ & Tablet & $61(30 \%)$ \\
\hline Windows & $13(6 \%)$ & $3-5$ & $78(39 \%)$ & Both & $59(29 \%)$ \\
\hline Others & $0(0 \%)$ & 6 or more & $8(4 \%)$ & Others & $18(9 \%)$ \\
\hline $\begin{array}{c}\text { Mobile } \\
\text { App } \\
\text { Shopping } \\
\text { Expenditur } \\
\text { e }\end{array}$ & Number (Percent) & $\begin{array}{c}\text { Frequency of } \\
\text { Using Mobile } \\
\text { App Shopping } \\
\text { in the last } 6 \\
\text { months }\end{array}$ & Number (Percent) & & \\
\hline 0 & $61(30 \%)$ & 0 & $5(2 \%)$ & & \\
\hline$\$ 1-100$ & $72(36 \%)$ & $1-3$ & $11(5 \%)$ & & \\
\hline$\$ 101-500$ & $50(25 \%)$ & $4-10$ & $64(32 \%)$ & & \\
\hline$\$ 501-1000$ & $17(8 \%)$ & $11-20$ & $92(46 \%)$ & & \\
\hline$>\$ 1000$ & $1(0.5 \%)$ & $>20$ & $29(14 \%)$ & & \\
\hline
\end{tabular}

In term of age, $51 \%$ were in the age range of 21 to 30 while $20 \%$ were below age 20 . In terms of gender, male was $51 \%$ while female was $46 \%$. $93 \%$ of all the respondents had at least the college education including bachelor or graduate degrees while $6 \%$ had the high school education. 93\% of respondents were using either Android (47\%) or Apple (46\%) phones. $71 \%$ of respondents had at least 1 or 2 mobile shopping apps on their smartphones. $31 \%$ of respondents used smartphones for mobile shopping while 30\% used tablets. $29 \%$ used both of smartphones and tables for their shopping. $61 \%$ of respondents spent $\$ 500$ or less for mobile shopping for the past 6 months while $8.5 \%$ spent more than $\$ 500.46 \%$ of respondents did shopping using mobile apps at the frequency of 11 through 20 for the past 6 months while $14 \%$ of them did at the frequency of more than 20 . Factor analysis was conducted to identify determinants for the continued use of mobile apps. As a result of factor analysis with Varimax rotation method, 32 items of instrument measurement were grouped into 9 factors. Cronbach's alpha, 0.93 was greater than 0.70 , which meant the research instrument was highly reliable. (Refer to Table 2)

Table 2. Factor Loading for the Continued Use of Mobile Apps Shopping

\begin{tabular}{|l|l|c|}
\hline \multicolumn{1}{|c|}{ Factors } & \multicolumn{1}{|c|}{ Measurement Instrument } & \multicolumn{1}{|c|}{$\begin{array}{c}\text { Factor } \\
\text { Loading }\end{array}$} \\
\hline \multirow{3}{*}{$\begin{array}{l}\text { Perceived } \\
\text { Usefulness }\end{array}$} & Mobile Apps shopping can support more shopping activities for me. (PU1) & 0.58279 \\
\cline { 2 - 3 } & Mobile Apps shopping reduces the time spent on those useless shopping activities. (PU2) & 0.49251 \\
\cline { 2 - 3 } & Mobile Apps shopping enhances my shopping effectiveness. (PU3) & 0.55857 \\
\cline { 2 - 3 } $\begin{array}{l}\text { Perceived } \\
\text { Ease of Use }\end{array}$ & Overall, Mobile Apps shopping is useful to personal shopping activities. (PU4) & 0.55926 \\
\cline { 2 - 3 } & It is easy to become skillful at using Mobile Apps Shopping. (PE1) & 0.61970 \\
\cline { 2 - 3 } & The interaction with Mobile Apps Shopping is clear and understandable. (PE2) & 0.81231 \\
\cline { 2 - 3 } & It is easy to perform the steps required to use Mobile Apps Shopping. (PE3) & 0.81418 \\
\cline { 2 - 3 } Enjoyment & It is easy to interact with Mobile Apps Shopping. (PE4) & 0.78753 \\
\cline { 2 - 3 } & Using m-commerce is enjoyable. (EN1) & 0.80875 \\
\cline { 2 - 3 } & Using m-commerce is pleasurable. (EN2) & 0.81066 \\
\cline { 2 - 3 } & I have fun using m-commerce. (EN3) & 0.77738 \\
\hline \multirow{2}{*}{$\begin{array}{l}\text { Security/ } \\
\text { Privacy }\end{array}$} & $\begin{array}{l}\text { The risk of an unauthorized third party overseeing the Mobile Apps Shopping process } \\
\text { is high. (SP1) }\end{array}$ & 0.52129 \\
\cline { 2 - 3 } & $\begin{array}{l}\text { The risk of abusing usage information (e.g. names of business partners, payment amount) } \\
\text { is high when doing Mobile Apps Shopping. (SP2) }\end{array}$ & 0.63064 \\
\hline
\end{tabular}




\section{Issues in Information Systems}

Volume 17, Issue II, pp. 34-43, 2016

\begin{tabular}{|c|c|c|}
\hline & $\begin{array}{l}\text { I would find Mobile Apps Shopping unsecure when payment transactions are conducted. } \\
\text { (SP3) }\end{array}$ & 0.76472 \\
\hline & I am concerned that downloading Mobile apps for shopping would be malicious apps. (SP4) & 0.74083 \\
\hline & $\begin{array}{l}\text { I believe my personal information (i.e. address, credit card, date of birth) would be } \\
\text { shared with other unauthorized third parties. (SP5) }\end{array}$ & 0.79439 \\
\hline & $\begin{array}{l}\text { I feel uncomfortable with the information being collected about me by the Mobile Apps } \\
\text { Shopping. (SP6) }\end{array}$ & 0.72417 \\
\hline & $\begin{array}{l}\text { I believe the information being collected during the Mobile Apps Shopping is more than } \\
\text { needed. (SP7) }\end{array}$ & 0.60699 \\
\hline \multirow{2}{*}{$\begin{array}{l}\text { Localization/ } \\
\text { Instant } \\
\text { Connectivity }\end{array}$} & $\begin{array}{l}\text { The product/service that I need at my current location can be supplied because of Mobile Apps. } \\
\text { (LO1) }\end{array}$ & 0.79399 \\
\hline & $\begin{array}{l}\text { I believe I will be able to search for the right information as soon as possible because of } \\
\text { Mobile Apps. (LO2) }\end{array}$ & 0.78968 \\
\hline \multirow[t]{2}{*}{$\begin{array}{l}\text { Personalizatio } \\
\mathrm{n}\end{array}$} & $\begin{array}{l}\text { I believe accessing to Mobile Apps Shopping would not require a lot of my mental effort. } \\
\text { (PE1) }\end{array}$ & 0.48019 \\
\hline & I believe Mobile Apps Shopping provide more personalized services. (PE2) & 0.36819 \\
\hline \multirow[t]{3}{*}{ Satisfaction } & I am satisfied with my decision to continue doing Mobile Apps Shopping. (SA1) & 0.34080 \\
\hline & My choice to continue doing Mobile Apps Shopping is wise. (SA2) & 0.53241 \\
\hline & I think I did the right thing by deciding to continue doing Mobile Apps Shopping. (SA3) & 0.53468 \\
\hline \multirow[t]{3}{*}{ Confirmation } & My experience of doing Mobile Apps Shopping was better than what I expected. (CF1) & 0.68636 \\
\hline & $\begin{array}{l}\text { The service level offered by Mobile Apps Shopping provider was better than what I } \\
\text { expected. (CF2) }\end{array}$ & 0.77257 \\
\hline & $\begin{array}{l}\text { Overall, most of my expectations of Mobile Apps Shopping approach were confirmed. } \\
\text { (CF3) }\end{array}$ & 0.70910 \\
\hline \multirow{3}{*}{$\begin{array}{c}\text { Continued } \\
\text { Intention to } \\
\text { Use Mobile } \\
\text { Apps } \\
\end{array}$} & I intend to continue do Mobile Apps Shopping rather than discontinue it. (CI1) & 0.81838 \\
\hline & $\begin{array}{l}\text { I am likely to continue Mobile Apps Shopping than any alternative means in the near } \\
\text { future. (CI2) }\end{array}$ & 0.69615 \\
\hline & I intend to continue Mobile Apps Shopping when the opportunity arises. (CI3) & 0.82407 \\
\hline
\end{tabular}

\section{Hypotheses Testing and Results}

Path analysis was conducted to test the hypotheses. (Refer to Table 3 and Figure 2)

Table 3. Hypothesis Results

\begin{tabular}{|c|c|c|c|}
\hline Hypothesis & Path & Path coefficient & t-value \\
\hline H1 & Confirmation -> Perceived Ease of Use & 0.76 & $7.45 * *$ \\
\hline $\mathrm{H} 2$ & Confirmation -> Perceived Usefulness & 1.13 & $8.73 * *$ \\
\hline H3 & Confirmation -> Enjoyment & 1.22 & $8.68 * *$ \\
\hline H4 & Confirmation -> Security/Privacy & 0.10 & 1.45 \\
\hline H5 & Confirmation -> Localization/Instant Connectivity & 0.28 & $2.13 *$ \\
\hline H6 & Confirmation -> Personalization & 0.82 & $7.32 * *$ \\
\hline $\mathrm{H} 7$ & Perceived Ease of Use $->$ Satisfaction & 0.25 & $3.71 * *$ \\
\hline $\mathrm{H} 8$ & Perceived Usefulness -> Satisfaction & 0.19 & $3.16^{* *}$ \\
\hline H9 & Confirmation -> Satisfaction & 0.31 & 1.71 \\
\hline H10 & Enjoyment $->$ Satisfaction & 0.20 & $4.57^{* *}$ \\
\hline H11 & Security/Privacy $->$ Satisfaction & -0.05 & -0.68 \\
\hline $\mathrm{H} 12$ & Localization/Instant Connectivity -> Satisfaction & -0.01 & -0.41 \\
\hline H13 & Personalization -> Satisfaction & 0.23 & $1.96^{*}$ \\
\hline H14 & Satisfaction $->$ Continued Intention to Use Mobile Apps & 0.94 & $12.62 * *$ \\
\hline \multicolumn{4}{|c|}{$\begin{array}{l}\text { Satisfaction R2: } 0.809 \\
\text { level }\end{array}$} \\
\hline \multicolumn{2}{|c|}{$\begin{array}{l}\text { Continued Intention to Use Mobile Apps R2: } 0.664 \\
\text { level }\end{array}$} & \multicolumn{2}{|c|}{ ** Significant at the 0.01} \\
\hline
\end{tabular}




\section{Issues in Information Systems \\ Volume 17, Issue II, pp. 34-43, 2016}

The relationship between confirmation and perceived ease of use was significant $(\mathrm{p}<0.01)$ and thus, H1is supported. There was significant relationship between confirmation and perceived usefulness $(p<0.01)$ and confirmation and enjoyment $(p<0.01)$ while the relationship between confirmation and security/privacy was not significant. The relationship between confirmation and localization/instant connectivity was significant at the p-value of 0.05 level while the relationship between confirmation and personalization was significant at the p-value of 0.01 level. Therefore, H1, H2, H3, H5, and H6 were supported while $\mathrm{H} 4$ was not. The relationship between perceived ease of use and satisfaction was significant $(\mathrm{p}<0.01)$, and the relationships between perceived usefulness and satisfaction was also significant $(\mathrm{p}<0.01)$ while the relationship between confirmation and satisfaction was insignificant. There is a significant relationship between enjoyment and satisfaction $(\mathrm{p}<0.01)$. There were no significant relationship between security/privacy and satisfaction, and between localization/instant connectivity and satisfaction. However, there is a significant relationship between personalization and satisfaction $(p<0.01)$ and between satisfaction and continued intention to use mobile shopping through apps $(\mathrm{p}<0.01)$. Therefore, H7, H8, H10, H13, and H14 were supported while H9, H11, and H12 were not. Moreover, about $81 \%$ of the variance in satisfaction $\left(\mathrm{R}^{2}=0.809\right)$ is explained by perceived ease of use, usefulness, confirmation, enjoyment, security/privacy, localization/instant connectivity, and personalization. On the other hand, $66 \%$ of the variance in the continued intention to use mobile apps is explained by satisfaction.

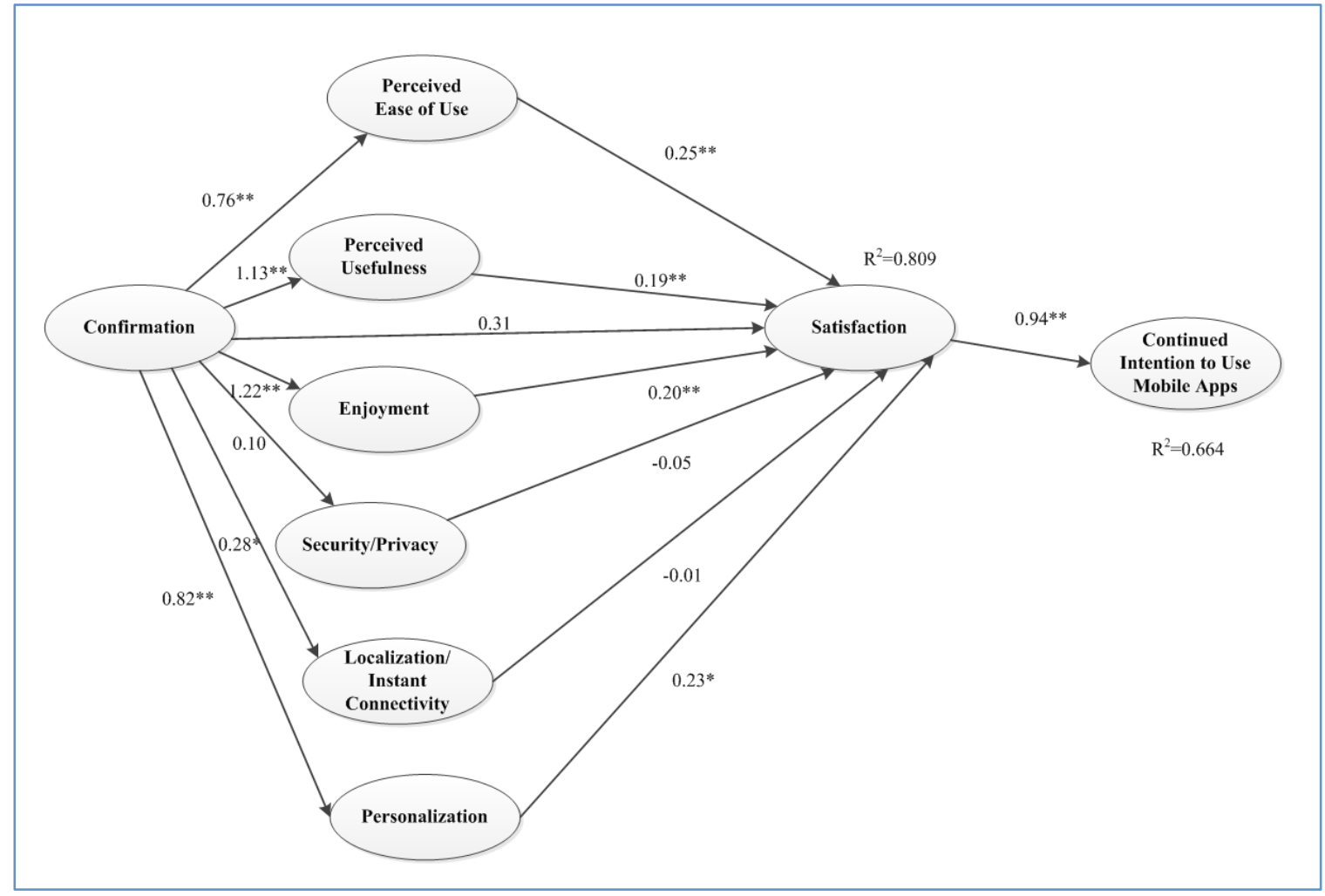

Figure 2. Path Diagram for Research Model

\section{Discussion}

The results of our research proved to be supportive of some of our hypotheses, which has given us a better understanding of what makes consumers continue to use mobile shopping apps. Because of the insignificance of the path coefficients of relationships between confirmation and security/privacy, between security/privacy and satisfaction, between localization/instant connectivity and satisfaction, between confirmation and satisfaction, we found that the continued intention to use of mobile shopping apps was directly linked to determining factors like perceived ease of use, perceived usefulness, enjoyment, and personalization. In Chong's (2013) study, it was found that confirmation had a significant influence on the continued use of mobile shopping apps, which was quite the opposite of our findings. Also, it was found that customers weren't very concerned about their security/privacy 


\section{Issues in Information Systems \\ Volume 17, Issue II, pp. 34-43, 2016}

when they are satisfied with the shopping experience while security/privacy continues to be one of the most important factors influencing customer's continuance intention (Hung et al, 2012). Satisfaction was found to be the most influential factor when it comes to the continued intention to use mobile shopping apps. This was also found to be true in previous studies. Hung et al (2012) stated that satisfaction was found to be directly linked to the continued intention to use mobile shopping apps. Perceived ease of use, usefulness, and enjoyment were also found to be important factors when it comes to satisfaction, which strongly affects the continued intention to use mobile apps. Chong (2012) argued that in the context of the mobile apps shopping, it is important to move beyond post adoption beliefs, that is, usefulness as performance oriented beliefs. Instead, pleasure related belief, that is, enjoyment should be focused. Finally, personalization was also found to be a very influential factor for the continued use of mobile apps while localization/instant connectivity was not significant. When customers have a more personalized service that caters specifically to their needs, they will continue to use mobile shopping apps.

\section{CONCLUSION}

While the initial ECM model is used popularly in predicting IS continuance, it is often questioned for the lack of intrinsic motivation. In this study, we added perceived ease of use, perceived enjoyment, security/privacy, localization/instant connectivity, and personalization as factors to extend the traditional ECM model. Although not all the proposed factors in this research have supported our hypotheses, they still have an important influence for us to understand consumers' continued intention to use mobile shopping apps. The results of our study also show that the continued intention to use mobile shopping apps is primarily dependent on the m-shoppers' satisfaction of mobile apps, which is also supported by previous studies by Thong, J.Y.L et al. (2006). Therefore, having satisfaction of mobile apps as a factor for the continued intention to use mobile apps is strongly valuable. To enhance the satisfaction, the study also shows that the factors such as perceived ease of use, usefulness, enjoyment, and personalization should exist in the m-shopping environment. They must be created and provided since all of them had a positive influence on satisfaction with the m-shopping. Because of the insignificance of the path coefficient, we can find that the satisfaction of m-shopping could not be directly determined by m-shoppers' confirmation. However, confirmation can be an important determinant of perceived ease of use, usefulness, enjoyment, localization/instant connectivity, and personalization. We still believe that confirmation also has indirect influence on the continued intention to use mobile shopping apps. This study has extended the ECM by including perceived enjoyment, which had been less emphasized before, but m-shopping apps are not only for purchasing but also for entertainment. Our findings show that enjoyment will increase m-shoppers' satisfaction, which leads to continued intention to use mobile shopping apps. All the results of this study can contribute to the m-shopping providers to establish friendlier m-shopping apps. Using the extended ECM model helps them to better understand determinants of m-shoppers' continued intention to use mobile apps. Therefore, m-shopping providers should ensure that shopping apps are user friendly, enjoyable, and trustworthy, which will eventually improve the performance of the apps for shopping products and service to satisfy users.

\section{Limitations of Study}

There are some limitations in our study. Firstly, surveyed data for the study was mostly collected in the mid-western area of U.S. To better generalize findings of how consumers continue to use mobile shopping apps, data should be collected from various countries with different aspects of factors including culture, morals, values, religion, and beliefs. Particularly, the subjective group norm was not considered in the study as a determinant for the continued use of mobile apps. Secondly, $94 \%$ of the participants had at least college education, which was not a good representation considering the education level of U.S. population. Many Americans without having college education still use mobile shopping apps. Therefore, the data used for the study may lead to biased results. 


\section{REFERENCES}

Bhattacherjee, A. (2001). Understand information systems continuance: An expectation-confirmation model. MIS Quarterly, 25(3), 351-370.

Chen, L. (2013). The quality of mobile shopping system and its impact on purchase intention and performance. International Journal of Managing Information Technology, 5(2), 1-8.

Chen, L. Y. \& Lauffer, W. H. (2010). The impact of mobile shopping quality on customer satisfaction and purchase intentions: The IS success based model. Proceedings of the International Institute of Informatics and Systemics Conference [online], Available http://www.iiis.org/CDs2012/CD2012SCI/SCI_2012/PapersPdf/MA553CN.pdf

Chen, Y., Yang, Huang, H., Hsu, Y. C., Tseng, H. C. \& Lee, Y. C. (2010). Confirmation of expectations and satisfaction with the Internet shopping: The role of Internet self-efficacy. Computer and Information Science, 3(3), 14-22.

Chong, A. Y. (2013). Understanding mobile commerce continuance intentions: An empirical analysis of Chinese consumers. Journal of Computer Information Systems, 53(4), 22-30.

Davis, F. D., Bagozzi, R. P. \& Warshaw, P. R. (1992). Extrinsic and intrinsic motivation to use computers in the workplace. Journal of Applied Social Psychology, 22(4), 1111-1132.

Gustafson, K. (2015). Retail apps becoming more popular with shoppers. CNBC [online], Available http://www.cnbc.com/2015/12/09/retail-apps-becoming-more-popular-with-shoppers.html

Hung, M., Yang, S. \& Hsieh, T. (2012). An examination of the determinants of mobile shopping continuance. International Journal of Electronic Business Management, 10(1), 29-34.

Islam, A., Khan, M. A., Ramayah, T. \& Hossain, M. M. (2001). The adoption of mobile commerce service among employed mobile phone users in Bangladesh: Self-efficacy as a moderator. International Business Research, 4(2), 80-89.

Liu, C., Marchewka, J. T., Lu, J. \& Yu, C. S. (2005). Beyond concern - A privacy-trust-behavioral intention model of electronic commerce. Information \& Management, 42(2), 289-304.

Lu, H. \& Su, Y. (2009). Factors affecting purchase intention on mobile shopping web sites. Internet Research, 19(4), 442-458.

Oliver, R. L. (1980). A cognitive model for the antecedents and consequences of satisfaction. Journal of Marketing Research, 17(4), 460-469.

Raisinghani, M.S. (2004). Chapter III. Mobile E-commerce and the Wireless Worldwide Web: Strategic Perspectives on the Internet's Emerging Model. In Shi, N. S. (Ed.). Wireless Communications and Mobile Commerce. Hershey: Idea Group, 49-79.

Thong, J.Y.L., Hong, S.J. and Tam, K.Y. (2006). The effects of post-adoption beliefs on the expectationconfirmation model for information technology continuance. International Journal of Human-Computer Studies, 64(9), 799-810. 